\title{
A Field Survey to Assess the Consumption of Nkang for Standardization and Valorization in the North-West Region of Cameroon
}

\author{
Acha Anna Afek ${ }^{1 *}$, Desobgo Zangue Steve Carly ${ }^{2}$, Nso Emmanuel Jong1 \\ ${ }^{1}$ Department of Process Engineering, National Advanced School of Agro-Industrial Sciences (ENSAI), University of Ngaoundere \\ Ngaoundere, Cameroon \\ ${ }^{2}$ Department of Food Processing and Quality Control of University Institute of Technology (UIT) of The University of \\ Ngaoundere, UIT, Ngaoundere, Cameroon \\ Email: ^achaafek@yahoo.com
}

How to cite this paper: Afek, A.A., Carly, D.Z.S. and Jong, N.E. (2021) A Field Survey to Assess the Consumption of Nkang for Standardization and Valorization in the North-West Region of Cameroon. Green and Sustainable Chemistry, 11, 107-123. https://doi.org/10.4236/gsc.2021.113010

Received: June 14, 2021

Accepted: August 22, 2021

Published: August 25, 2021

Copyright $\odot 2021$ by author(s) and Scientific Research Publishing Inc. This work is licensed under the Creative Commons Attribution International License (CC BY 4.0).

http://creativecommons.org/licenses/by/4.0/

(c) (i) Open Access

\begin{abstract}
In African communities, traditional beer drinking remains a unifying factor within its populations both socially, commercially, culturally, politically, in health and nutrition and for some ritual practices. In this research a field survey was carried out to investigate the consumption of corn beer and in particular Nkang in the North-West Region of Cameroon. The tools that were employed to carry out these investigations included face-to-face interviews and the use of properly designed questionnaires. Results from the survey showed that three types of maize-based beverages are drunk in the North-West Region of Cameroon, which are locally called Kwacha (whitish, most viscous and most turbid), Sha-ah (cream white, viscous and turbid) and Nkang (dark brown, least viscous and least turbid) in terms of colour, viscosity and turbidity. The percentage awareness of the existence of these beers from the sampled population gave the following values; $60.9 \%$ for Kwacha, $100 \%$ for Sha-ah and $89.1 \%$ for Nkang. Nonetheless, $54.5 \%$ of the $60.9 \%$ of those who were aware of the existence of kwacha had at least tasted it. Also $98.2 \%$ out of the $100 \%$ for Sha-ah and $85.5 \%$ out of $89.1 \%$ for $N k a n g$ had tasted them, too. Nkang was found to be the most preferred to Sha-ah then $K w a c h a$ in that order by the consumers since Nkang is very tasteful, least alcoholic, least turbid, least viscous, has the most attractive colour than the others, has a significant impact on the culture of some localities in this region and as well as it is natural and nutritious. However, Nkang as well as the other two has varying organoleptic properties, unsatisfactory conservation and short shelf-life. Hence are consumed within a short period of time from their production. Because of the low alcoholic content of Nkang, the beverage is consumed by both adults (most elderly), children, those who have health problems and it is mostly preferred by some Christians though not frequently
\end{abstract}


seen in the markets. It was equally observed that the little quantity of Nkang found in the markets is of poor quality which keeps dropping everyday thus an indication of its risk becoming extinct. Therefore, if Nkang is clarified and its quality improved, the problems can be solved as even attested by the consumers who say they will buy at even a higher price if clarify. As well as those who want it for their cultural reasons do not want it to face out too.

\section{Keywords}

Corn Beer, Kwacha, Sha-ah, Nkang, Alcoholic Content, Least Viscous, Shelf-Life

\section{Introduction}

Indigenous fermented products play an important role in the diet of most people in the developing countries [1]. An example of these indigenous fermented products is beer which has become a staple part of the diet in many cultures [2]. The traditional African sorghum beers are very rich in calories, B-group vitamins including thiamine, folic acid, riboflavin, and nicotinic acid, and essential amino acids such as lysine [3] [4]. Beer has been found to increase the plasma high-density lipoprotein (HDL) which is a scavenger of cholesterol thus reducing risk of cardiovascular diseases, gallstones and stomach ulcers and protection of brain against mental decline due to aging [5]. It is also a tonic, nutritive, digestive, appetizer, soothing and sedative beverage [6]. It is galactogene thus a small quantity is good for pregnant and lactating women. The beers are consumed at various festivals and African ceremonies such as marriages, births, baptism ceremonies, the handing over of a dowry, are very important for political, social and for economic interactions inter alia as well as constituting a source of economic return for the female beer producers [7]. Beer differs in its significance, acceptability and importance from culture to culture. Other examples of these African traditional beers include; ikigage in Rwanda [8], tchoukoutou in Benin and Togo [9], dolo in Burkina Faso [10], pito or burkutu in Nigeria and Ghana and amgba in Cameroon as well as maize-based beers (generally called corn beer) of various types such as Nkang which are often consumed in the North West Region of Cameroon. Nkang which is one of the corn beer types has some cultural affiliations to the people of Bali, one of the ethnic groups found in the North-West Region of Cameroon pointing out the degree of cultural attachment to Nkang by the people of this locality. However, traditional African beers are generally "opaque" beers [11], less attractive than Western beers brewed with barley malt because of their relatively poor hygienic quality, low ethanol content (usually less than $5 \% \mathrm{v} / \mathrm{v}$ ), organoleptic variation and unsatisfactory conservation [8] [12]. Nkang and related locally made alcoholic beverages suffer the same fate. To overcome these constraints, some of these African traditional beers have been industrialized by standardizing their production 
processes, for example Star Lager (Nigerian Beer), Tusker Lager (Kenyan Beer), Castle Lager (from South Africa), Casablanca, (Moroccan Beer) [10]. In the same light, because of its cultural significant, if Nkang beer production process can be standardized and documented as no literature is found on, this will go a long way to prolong its shelf-life [13]. To standardize such a process, a survey on its consumption from those who drink it is sine qua none to upgrading the beer in terms of production, shell-life enhancement and quality enhancement and assurance and thus standardizing the product, since some sensory qualities and preferential appreciations can be investigated [14] [15]. This study was aimed at carrying out a field survey on the consumption of corn beer and in particular Nkang beer in the North-West Region of Cameroon and using the results to attempt to design a standardization scheme for Nkang.

\section{Materials and Method}

\subsection{Materials}

Questionnaires were used for data collection. Software Sphinx V5 was used to format the questionnaires, treat and analyzed the data collected from the field.

\subsection{Study Area}

The survey was carried out in four Divisions (Bui, Mezam, Momo, Ngoketunjia), with co-ordinates in degree, minutes, seconds as $10^{\circ} 0^{\prime} 0^{\prime \prime}$ to $11^{\circ} 0^{\prime} 0^{\prime \prime} \mathrm{E}$ Latitudes and $6^{\circ} 0^{\prime} 0 "$ to $6^{\circ} 30^{\prime} 0 " \mathrm{~N}$ Longitude using the WJS 84 system of projection, chosen from the seven Divisions of the North-West Region of Cameroon considered to be the prime areas where Nkang is drunk most going by the number of people involved in such activities and the population of these areas.

\subsection{Methods}

In order to deduce the quality of corn beer the inhabitants of the North West are exposed to, one hundred and ten (110) corn beer consumers were identified and interviewed by administering questionnaires within the chosen study area. Eighty-six (86) questions each per questionnaire were developed with the idea of checking on the quality of corn beer types and the consumption sustainability of the corn beer with emphasis on Nkang. The questions were grouped under five sub-sections:

\subsubsection{Socio-Economic Status}

To know the type of people who drink corn beer and particularly Nkang, their age group, sex, and occupation to evaluate the preference given to domestic products and to see how many people love adhere to tradition or prefer the so called modernism.

\subsubsection{Consumers General Knowledge on Corn Beer and the Various Types}

$\checkmark$ Here we wish to know whether the present generation knows the type of local 
beers that existed before and how many do exist.

$\checkmark$ To verify if those who know these beers have even tasted any.

$\checkmark$ To see if they know the starting raw material for corn beer production?

$\checkmark$ Degree of awareness with Age group, to see whether those who are aware and have tasted these corn beers do vary with the age group.

$\checkmark$ To rate the drinking of corn beer with age group thus identify which age group drinks highest.

$\checkmark$ To have knowledge of the sensory attributes of the corn beer types. To see if the consumers can identify these corn beer types in terms of colour, taste, cloudiness (turbidity) and viscosity.

$\checkmark$ Preference for these corn beer types; to know which type do they prefer and why?

$\checkmark$ Reasons for not drinking any of these corn beers; to know why some consumers do not drink all of the three types of corn beer and to know the qualities of the type of beer they want.

$\checkmark$ Comparing their love for corn beer to other available industrial beers in the market and why?

\subsubsection{Particular Knowledge and Quality of Nkang and Its Marketability}

$\checkmark$ How many people have actually tasted Nkang and their reactions and to identify those aspects which they like or dislike about Nkang.

$\checkmark$ Some preferred attributes of Nkang by the consumers.

$\checkmark$ Other quality aspects of Nkang; to know whether the consumers like clarified Nkang and why?

$\checkmark$ Desire Qualities of Nkang; to know which aspects of $N k a n g$ will they like the producers to work on so as to improve on its quality?

$\checkmark$ To see if Nkang is frequently found in the market?

$\checkmark$ To rate whether the purchasing power of the consumers depend on the price or quality of the beer? How much they can offer for a liter of Nkang?

$\checkmark$ To check on whether their preference for one bar to another depends on the quality or price of the beer per bottle?

$\checkmark$ To verify if Nkang is clarified, will they buy it or not?

\subsubsection{Knowledge on Nkang Production from Consumer's View}

$\checkmark$ To see if there are some consumers who know how to produce Nkang.

$\checkmark$ To know who taught them? (i.e. source of technology transfer)

$\checkmark$ To investigate why some do not know how to produce Nkang though it is locally made? (i.e. to see the degree of negligent on their custom and culture)

\subsubsection{Some Cultural Aspects of Nkang}

$\checkmark$ To see if Nkang has an impact on their culture and to what extent?

$\checkmark$ Do they wish this tradition of Nkang production for cultural reasons to continue?

$\checkmark$ What is their opinion on Nkang if it is substituted with red wine or Whiskey? 


\section{Results and Discussions}

\subsection{Socio-Economic Status}

A demographic representation of Corn Beer consumers in the North West Region of Cameroon is as shown on Table 1.

From Table 1, corn beer is consumed by both men and women with a percentage of $53.6 \%$ and $46.4 \%$ respectively in conformity with the report of [16]. Considering the age groups, from the highest to the least age group in terms of drinking corn beer, we have from 30 - 50, 50 - 65, 65 and above, 20 - 30 and then to 15 - 20 showing that the younger generation does not like drinking it as shown by a $0.9 \%$ for those between 15 - 20 years and $12.7 \%$ for those between 20 - 30 years, indicating a gradual shift from culture to modernism with age [17]. It can also be observed from the table that the highest consumers are from Momo

Table 1. Demographic characteristics of consumers of corn beer.

\begin{tabular}{|c|c|c|}
\hline Variable & Group & Percentage (\%) \\
\hline \multirow{2}{*}{ Sex } & Female & 46.4 \\
\hline & Male & 53.6 \\
\hline \multirow{5}{*}{ Age } & $15-20$ & 0.9 \\
\hline & $20-30$ & 12.7 \\
\hline & $30-50$ & 44.5 \\
\hline & $50-65$ & 25.5 \\
\hline & 65 and above & 16.4 \\
\hline \multirow{5}{*}{ Division of Origin } & Momo & 48.2 \\
\hline & Mezam & 30.9 \\
\hline & Ngoketunjia & 13.6 \\
\hline & Bui & 4.5 \\
\hline & Menchun & 1.8 \\
\hline \multirow{5}{*}{ Level of Education } & None scholar & 8.2 \\
\hline & Primary & 50 \\
\hline & Standard & 4.5 \\
\hline & Secondary & 26.4 \\
\hline & University & 10.9 \\
\hline \multirow{7}{*}{ Occupation } & Farmer & 44.6 \\
\hline & Civil servant & 12.3 \\
\hline & Non-public Workers & 2.3 \\
\hline & Private worker & 13.8 \\
\hline & Business & 16.2 \\
\hline & Non-Workers & 6.2 \\
\hline & Retired Civil servant & 4.6 \\
\hline
\end{tabular}


origin, most of them having primary school level of education and are mostly farmers, showing the population settlement at the local level.

\subsection{Consumer's General Knowledge on Corn Beer and the Various Corn Beer Types}

The general knowledge of the various types of corn beer is depicted in terms of percentage of sampled population by Figure 1 .

From Figure 1, three types of corn beer (kwacha, sha-ah and Nkang) do exist with the percentage awareness by consumers of $60.9 \%$ for Kwacha, $89.1 \%$ for Nkang and $100 \%$ for Sha-ah. These show that Sha-ah is the most popular and available than Nkang and then Kwacha. However, $54.5 \%$ of the $60.9 \%$ of those who are aware of the existence of Kwacha has at least tasted it, same as $98.2 \%$ out of the $100 \%$ for Sha-ah and $85.5 \%$ out of $89.1 \%$ for Nkang as shown on Figure 2. From this observation we can say that, the actual Population of those who have at least tasted any of these three types of corn beer is lower than those who are aware of their existence indicating that not everybody that knows about the existence of these beers has tasted it. Therefore, the present generation at least has an idea of locally produced corn beer. As for the starting raw material for corn beer production, $65.4 \%$ say that it is corn, $23.1 \%$ talk of germinated corn thus they are aware that the beer is from corn. This is also an indication of some degree of preference for domestic beverages [18].

\subsection{Those Who Have at Least Tasted Any of These Three Types of Corn Beer}

From Figure 2, Sha-ah is the most popular corn beer type in the study area and closely followed by Nkang and then Kwacha showing how the knowledge on Nkang and Kwacha is dying down thus a point of concern, see Figure 3.

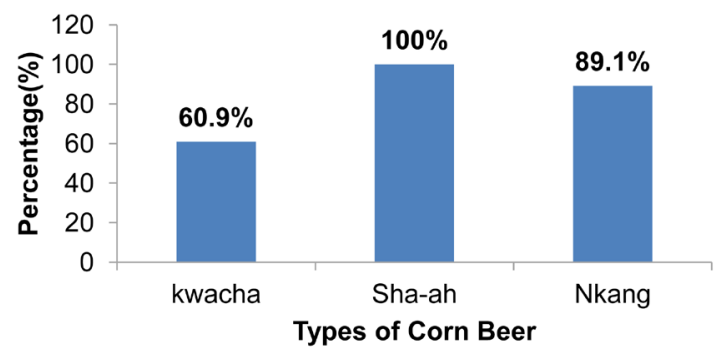

Figure 1. Percentage awareness of corn beer types.

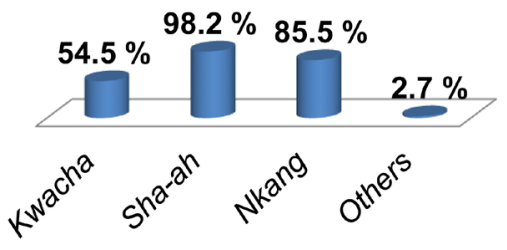

Corn beer type tasted at least

Figure 2. Percentages of those who have at least tasted any of these three corn beer types. 


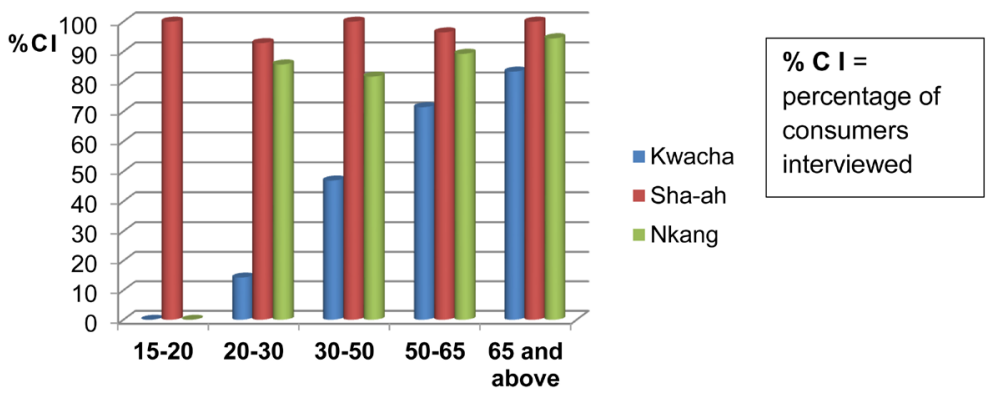

Figure 3. Awareness of consumers and their knowledge on corn beer types versus age group.

\subsection{Degree of Awareness with Age Group}

Figure 3, shows that the degree of awareness by the consumers of kwacha and Nkang increases from the age group 20 - 30 up to 65 and above, with no person within the age group 15 - 20 years knowing Kwacha and Nkang. This is an indication of the ebbing awareness of Nkang and Kwacha as generation pass on. On the other hand, all age groups interviewed have an idea of sha-ah meaning that it is the only corn beer type known by all at moment.

\subsection{Rate of Drinking Corn Beer with Age Group}

The actual Population that have at least tasted any of these corn beers within each group with the highest being those of the age group 30 to 50 years is as shown on Figure 4. It can also be observed from the figure that the drinking ability decreases on both sides of the age group 30 - 50, per each beer type showing that it is the active age group that drinks the highest. Hence if Nkang and related corn beers are standardized, they will be demanded and consumed by the active population which exceeds the other age groups [19].

\subsection{Knowledge on Some Sensory Attributes of the Corn Beer Types}

It can be observed from Figure 5, that Kwacha is whitish in colour, Sha-ah is cream white and Nkang is dark brown. As for the taste attributes, Kwacha is not sweet, Sha-ah is sweet and Nkang is very sweet. While kwacha is very viscous, Sha-ah is less viscous and Nkang is least viscous. Considering turbidity, Kwacha is very turbid, Sha-ah is turbid and Nkang is least turbid [20]. Thus prospect increase in Nkang's shelf life as filtration is improved and faster throughput [21]. This shows that the consumers can easily identify these beers types from their sensory attributes [22].

\subsection{Preference for These Corn Beer Types}

Table 2, shows the various percentages for the reasons why the consumers prefer drinking each of the three types of corn beer. $100 \%$ of those who drink Kwacha prefer it because it serves as food (makes their stomach full) and, $57.1 \%$ say it is more alcoholic than the other two and $57.1 \%$ also say they have the habit of 


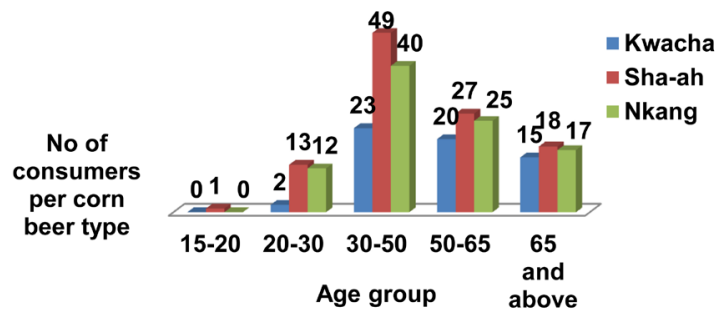

Figure 4. Number of interviewers who have at least tasted the various types of corn beer within each age group.

Table 2. Preference for each corn beer type by the consumers.

\begin{tabular}{|c|c|c|}
\hline Corn Beer Type & Preference for each corn beer type & Percentage affirmative \\
\hline \multirow{7}{*}{ Kwacha } & It is not sweet & $14.30 \%$ \\
\hline & More alcoholic than others & $57.10 \%$ \\
\hline & It is a habit & $57.10 \%$ \\
\hline & It's the cheapest & $14.30 \%$ \\
\hline & The heaviest( most viscous and turbid) & $42.90 \%$ \\
\hline & Serves as food & $100.00 \%$ \\
\hline & Does not cause running stomach & $14.30 \%$ \\
\hline \multirow{12}{*}{ Sha-ah } & Sweeter than Kwacha too sweet as Nkang & $37.50 \%$ \\
\hline & Less alcoholic than Kwacha & $41.10 \%$ \\
\hline & More alcoholic than Nkang & $16.10 \%$ \\
\hline & Good taste & $76.80 \%$ \\
\hline & Has an attractive colour & $53.60 \%$ \\
\hline & It is a habit & $69.60 \%$ \\
\hline & It is available (easy to find) & $78.60 \%$ \\
\hline & Good for my system & $41.10 \%$ \\
\hline & Serves as food & $85.70 \%$ \\
\hline & It's Cheap & $46.40 \%$ \\
\hline & Knows how to produce it & $19.60 \%$ \\
\hline & Due to scarcity of Nkang in the market & $19.60 \%$ \\
\hline \multirow{11}{*}{ Nkang } & It is very sweet & $66.70 \%$ \\
\hline & Has a very good taste & $96.10 \%$ \\
\hline & least alcoholic than all & $94.10 \%$ \\
\hline & It is clear(least turbid) & $92.20 \%$ \\
\hline & Least viscous & $94.10 \%$ \\
\hline & Has an attractive colour & $90.20 \%$ \\
\hline & Satisfactory as food & $72.50 \%$ \\
\hline & Quenches thirst & $54.90 \%$ \\
\hline & Gives pleasure & $52.90 \%$ \\
\hline & Knows how to produce it & $19.60 \%$ \\
\hline & Do not causes any health problems & $62.70 \%$ \\
\hline
\end{tabular}




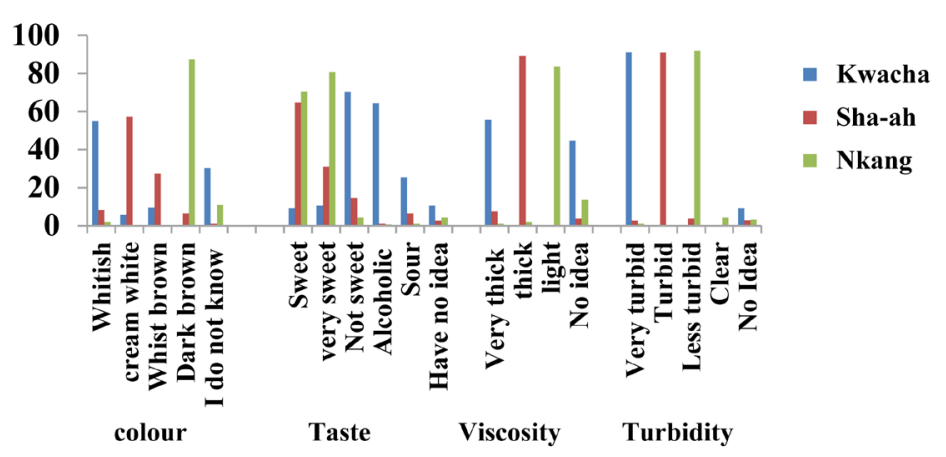

Figure 5. Some sensory attributes of the three types of corn beer.

drinking it. While $42.90 \%$ prefer drinking Kwacha because it is more viscous and turbid. These are indications to show that Kwacha is the most turbid, viscous and most alcoholic amongst the three types of corn beer confirming the information on Figure 5 for Kwacha. Different physical with attendant chemical properties leads varied preferences for locally brewed drinks and is a function of demand for the products [23]

Considering those who like drinking Sha-ah, $85.70 \%$ like drinking it because it serves as food 'so it fills their stomach' but not as kwacha does. $78.60 \%$ say Sha-ah is more available indicating the most popular and the most available than the others as also indicated on Figure 1,76.80\% says it has a good taste i.e. good mouth-feel, $69.60 \%$ says it is a habit, $41.10 \%$ says it is good for their system, $41.10 \%$ says it is less alcoholic than Kwacha, $37.50 \%$ say it is sweeter than Kwacha and not too sweet as Nkang meaning that Sha-ah is not too sweet and has moderate alcoholic content from the other two.

As to those who prefer drinking Nkang, $96.10 \%$ says it has a very good taste, $94.10 \%$ says it is less alcoholic, $94.10 \%$ says it is least viscous, $92.20 \%$ says it is clear that is least turbid, thus it easy to drink as they do not feel particles at the throat during drinking as its the case with the other two, $90.20 \%$ say it has an attractive colour, $66.70 \%$ says it is very sweet, these imply that $N k a n g$ has a very good taste, nice colour and is sweet. 19.60\% know how to produce it showing that only a small population knows the Nkang production technology.

\subsection{Reasons for Not Drinking Any of These Corn Beer}

Table 3 shows why some people will not like to drink any or all of these corn beer types. We can observe that, $66.90 \%$ of the consumers do not like drinking Kwacha and $64.80 \%$ for Sha-ah because they feel particles at the throat during drinking, $45.60 \%$ for Kwacha and $42.60 \%$ for sha-ah talk of them to be too heavy and thick as food not as a drink (i.e. they are viscous and turbid) as they have to chew before swallowing. $42.70 \%$ say Kwacha needs to be heated before drinking showing how viscous kwacha is while $25.40 \%$ say $N k a n g$ is least viscous as it can be compared to water [24]. $42.70 \%$ say they do not know Kwacha with $15.30 \%$ not also knowing Nkang and $33.90 \%$ say Nkang is not available indicating their scarcity in the markets. From these observations we can say that kwacha and 
Table 3. Deterrents from corn beer products.

\begin{tabular}{|c|c|c|}
\hline Corn beer type & $\begin{array}{l}\text { Reasons for not drinking any } \\
\text { of the corn beer type }\end{array}$ & $\begin{array}{l}\text { Percentages } \\
\text { disapproval }\end{array}$ \\
\hline \multirow{7}{*}{ Kwacha } & Too heavy \& thick as food not as a drink & $45.60 \%$ \\
\hline & Colour and taste not appreciable & $34.00 \%$ \\
\hline & High alcoholic content than others & $43.70 \%$ \\
\hline & Feel particles not easy to drink & $66.90 \%$ \\
\hline & Not sweet & $36.90 \%$ \\
\hline & Need to be heated before drinking & $42.70 \%$ \\
\hline & Don't know it & $42.70 \%$ \\
\hline \multirow{6}{*}{ Sha-ah } & Heavy \& thick as food not as a drink & $42.60 \%$ \\
\hline & Colour and taste not appreciable & $46.30 \%$ \\
\hline & High alcoholic content & $42.60 \%$ \\
\hline & Feel particles not easy to drink & $64.80 \%$ \\
\hline & Not sweet & $27.80 \%$ \\
\hline & Provokes vomiting & $13.00 \%$ \\
\hline \multirow{6}{*}{ Nkang } & Least viscous can be liken to water & $25.40 \%$ \\
\hline & Has less alcoholic content & $8.50 \%$ \\
\hline & Too sweet & $22.00 \%$ \\
\hline & Not available (cannot easily be seen ) & $33.90 \%$ \\
\hline & Don't know it & $15.30 \%$ \\
\hline & Poor quality & $10.20 \%$ \\
\hline
\end{tabular}

Nkang are scare in the markets and that the population want beer that is least turbid and least viscous indicating that a clarify corn beer will be preferred as confirmed by Figure 8. On the other hand they population wish that corn beer should have moderate alcoholic content as can be deduced from the following observations; $43.70 \%$ says kwacha has a high alcoholic content than others, $42.60 \%$ say same for sha-ah while a very small percentage of $8.5 \%$ say $N k a n g$ has the least alcoholic content with $22.0 \%$ saying that Nkang is too sweet. Therefore the consumers dislike corn beer that has high alcoholic content, viscous and turbid, but are comfortable with that which is sweet with moderate alcoholic content [25].

\subsection{Relative Desire for Corn Beer}

From Figure 6; $87.30 \%, 86.40 \%, 84.50 \%, 77.30 \%, 71.80 \%, 69.10 \%, 69.10 \%$, $68.20 \%$ of the population says that they love drinking corn beer to industrial beer because it serves as food, more nutritive, natural, cheaper, has good taste, low alcoholic content, know its raw materials and to consume local products respectively. While $31.80 \%$ which falls below average says that they drink corn beer because it is available meaning that corn beer is scare in our markets. Also, 


\section{Preference for corn beer to industrial beer}

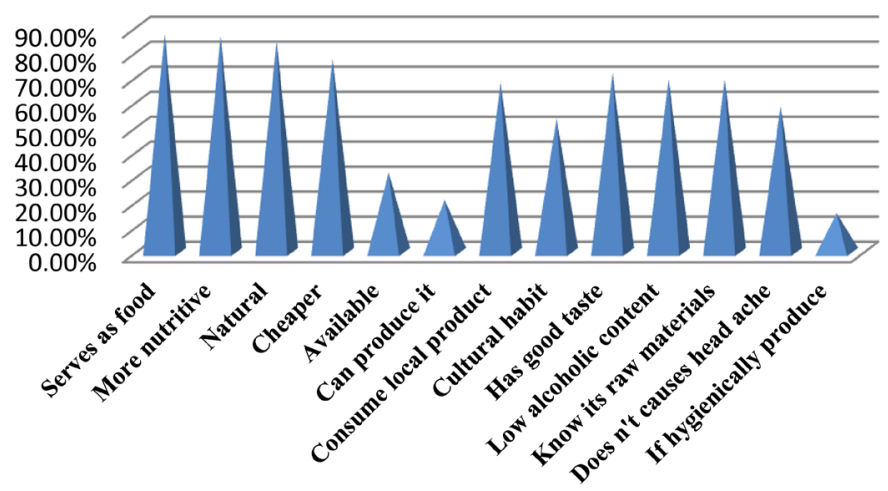

Figure 6. Preference for corn beer to industrial beer.

only $20.90 \%$ of the consumers know how to produce any of the corn beer type meaning that there are lesser producers reason why the product is rare in the market. $15.50 \%$ says if corn beer is hygienically produced, they will like it meaning that corn beer has some unhygienic aspects but has upgrading potentials.

From Figure 7, 50.0\%, 49.10\%, 49.10\%, 47.30\%, 46.40\% of the Population interviewed love industrial beer because it looks more hygienic, well made, of high quality, less turbid, less viscous and well packaged respectively than corn beer. While $70.90 \%$ say they do not prefer industrial beer to corn beer meaning they still love corn beer even if it does not have the above mentioned qualities as the industrial beer. This indicates that though many people love industrial beer because of its quality, they still have an attachment of great love for traditionally made products. This is corroborated by the low $14.50 \%$ for those who love industrial beer because it is modern.

\subsection{Particular Knowledge and Quality of Nkang and Its Marketability}

85.5\% of the consumers have actually tasted Nkang as from Figure 2, with a $67.3 \%$ and $42.7 \%$ haven tasted it from the market and their homes respectively.

Nkang is most preferred by the consumers as can be seen from Table 2 (with the highest percentages) and Table 3 (with the lowest percentages) with their preference for Nkang to sha-ah and kwacha as shown on Table 4.

\subsection{Nkang Clarification, Standardization and Valorization}

$95 \%$ of the population wish that Nkang should be clarifieddd according to Figure 8 because it will look attractive as $96.8 \%$ consumers affirmed, $87.3 \%$ says it will improve its quality, $81.0 \%$ say it would be conserved easily, $79.4 \%$ says clarification will make it portable as it can be bottled and $90.5 \%$ talk of increase in its shelf life thus standardizing Nkang and hence quality control [26].

Considering Figure 9 with blocks A, B, C; 73.60\% say they cannot produce Nkang with just $21.80 \%$ that can, thus technology not known by all. From block B, $70.80 \%$ of the $21.80 \%$ that knows how to produce Nkang learnt it from their 
$\%$ Preference for industrial beer to corn beer

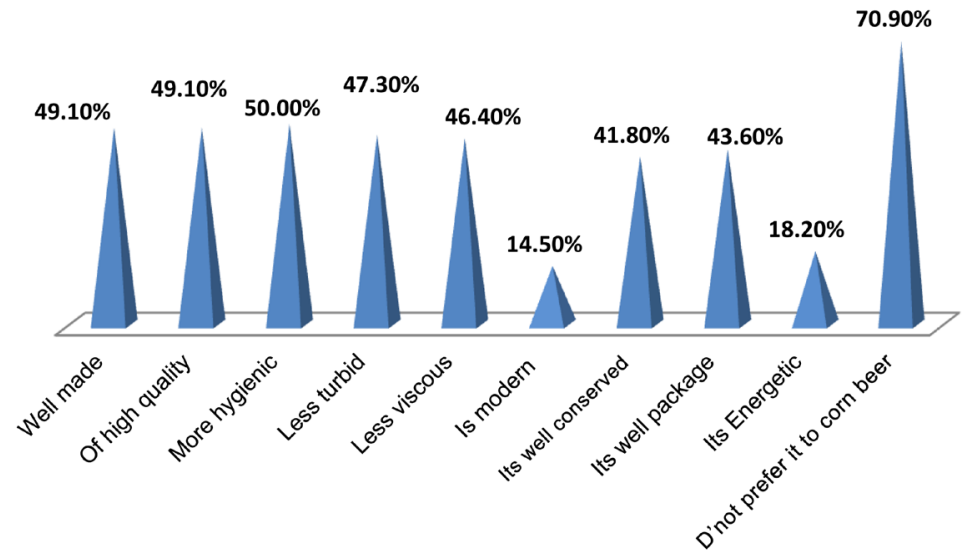

Figure 7. Preference for industrial beer to corn Beer.

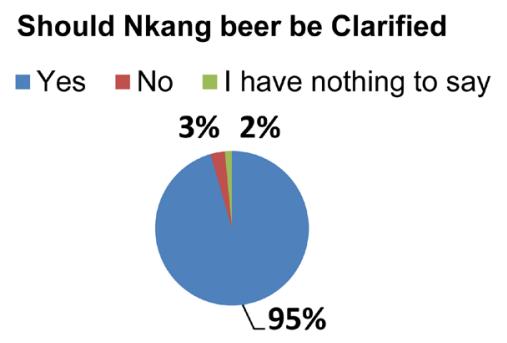

Figure 8. Acceptability for Nkang to be clarified in percentages.

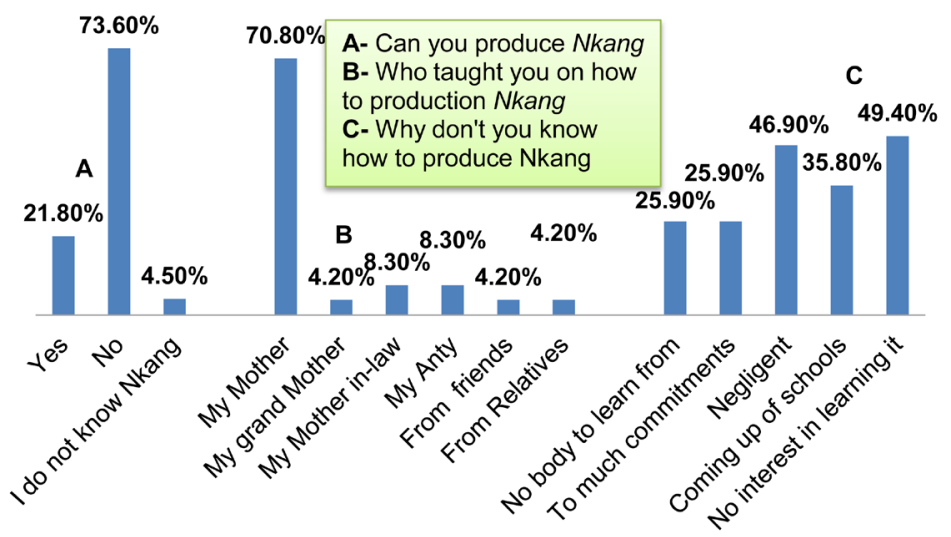

Figure 9. Consumer's production know-how and source of technology transfer.

Table 4. Preference for Nkang to Sha-ah and Kwacha.

\begin{tabular}{cc}
\hline Preference for Nkang to sha-ah and kwacha & Score in Percentage (\%) \\
\hline Very tasteful & 54.6 \\
Least alcoholic & 55.5 \\
Least turbid & 54.6 \\
Least viscous & 55.5 \\
Has an attractive colour & 51.8 \\
Has an impact on the culture & 60.0
\end{tabular}


mothers, $8.30 \%$ from mother in-law and $4.20 \%$ from their grandmothers indicating that mostly women are involved in the production of Nkang [7] [27] and that the technology is a hand down process from parent to children without documentation. $49.40 \%$ have no interest in learning on how to produce Nkang, $46.90 \%$ are negligent, $35.80 \%$ says with the coming up of schools they do not have time to learn it as well as those who are too committed with other things that make up $25.90 \%$ and no body to learn from that make up $25.90 \%$, too. This is an indication that the technology is dying out thus need to be valorize.

Although Nkang is not frequently found in the markets with a $77.3 \%$ as shown on Figure 10, some consumers that make up $72.90 \%$ from Figure 11, point out that this is due to less producers and a $61.20 \%$ saying that they believe that the technology is not well transferred to the children as those who say it is due to poor quality thus drop in the market make up $37.60 \%$, However, $22.40 \%$ of the consumers attribute it to the death of most of the producers which can be confirmed with the $36.5 \%$ who says that the Nkang beer is mostly produced by older women. Nonetheless, $58.80 \%$ say it is due to the coming up of schools and $54.10 \%$, talk of coming up of many other types of drinks especially sweet drinks but it seems the present generation has no interest in its production as shows on Figure 11 , with a $7.10 \%$.

\subsection{Purchasing Power with the Price or the Quality of the Beer}

According to Figure 12, 86.40\% of the consumers say that, their purchasing power is a function of the price/quality ratio of the beer. $85.50 \%$ say they drink Nkang not because of the price but because of the quality of the beer that is the overall sensory attributes and its nutritious nature. With respect to bar preference, $89.10 \%$ say that they like one bar to another depending on the quality, $83.60 \%$ like the quality of services, $80.00 \%$ cleanness and neatness of the bar and the shop owner, $63.60 \%$ say it depends on the availability of the beer. Thus their purchasing power and drinking habit is a function of the quality and not the price [28].

\subsection{Cultural Attachment to Nkang}

We can observe from Figure 13 that, $92.40 \%$ of the consumers say Nkang drinking should continue so as to preserve their cultural values. While $80.30 \%$, $66.70 \%, 50.00 \%$ also attest that Nkang drinking, should be promoted because it serves as a unifying factor, source of entertainment and to maintain their tradition, respectively [29]. 13.60\% says that according to their tradition and custom

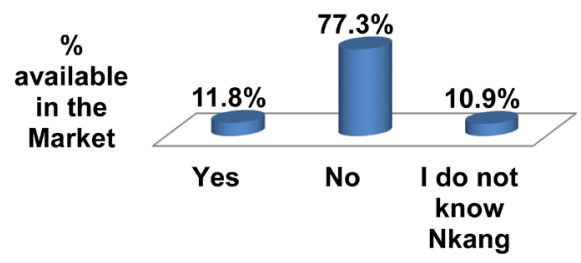

Figure 10. Percentage availability of Nkang in the Markets. 
$\%$ Scarcity of Nkang in the Markets

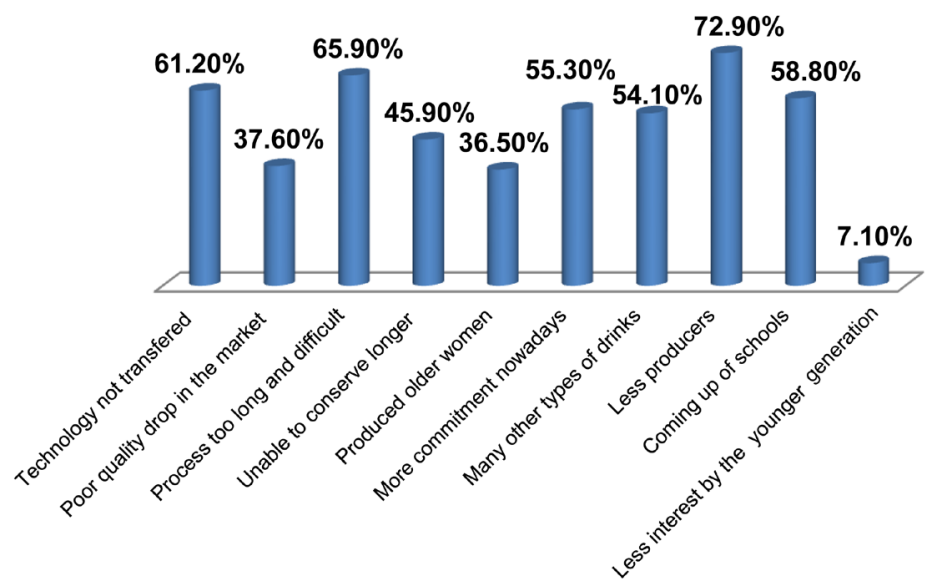

Figure 11. Why Nkang is scare in the market in percentages.

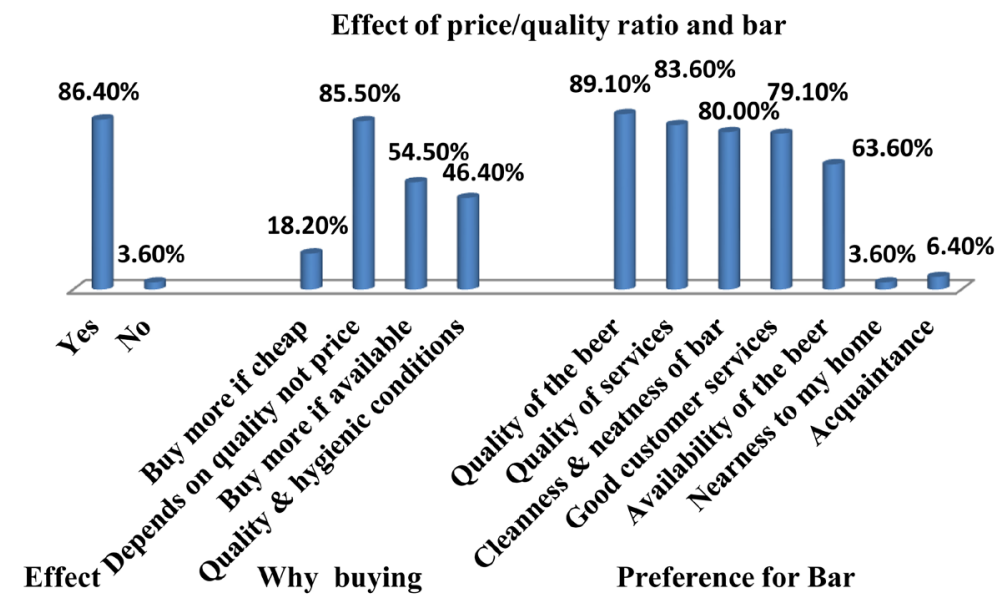

Figure 12. Effect of price/quality ratio and bar with their drinking habit.

Impact of Nkang on the culture

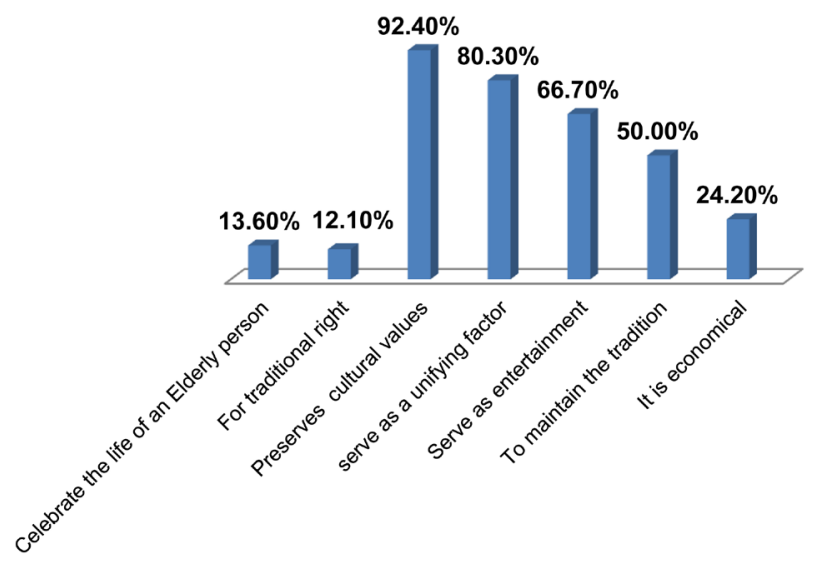

Figure 13. Cultural impact of Nkang.

Nkang must be prepared when an elderly person of rightful age dies and $12.10 \%$ uses Nkang for traditional rights. 
Further investigation was made to see if the consumers will like Nkang to be replaced with red wine or whiskey for rituals and there was a $100.0 \%$ dislike by the consumers. When asked why; the following responses were got; $98.2 \%$ saying that they have to promote their cultural, $85.5 \%$ says its dignity be preserved for continuity, $83.6 \%$ says it is natural, $83.6 \%$ says it can serve many people at a time, $81.8 \%$ say it is produced locally, $69.1 \%$ says their culture must be conserved, $60.0 \%$ talk of Nkang being nutritious and $58.2 \%$ less alcoholic than the red wine.

\section{Conclusion}

Results from the survey show that corn beer locally made beer, as well as palm wine and industrially produced beer from barley are consumed in the North-West Region of Cameroon. Three types of corn beer kwacha, sha-ah and Nkang do exist with Sha-ah being the most popular, most available but with Nkang, the most appreciated by the consumers. On the other hand, Kwacha and Nkang are not frequently seen in the markets. This is an indication of them running the risk of extinction. Kwacha is more turbid and viscous than Sha-ah and then Nkang. Kwacha is whitish, Sha-ah is cream white and Nkang is dark brown in colour. Nkang is the most preferred to Sha-ah and then Kwacha by the consumers due to the fact that Nkang is very tasteful, least alcoholic, least turbid, least viscous, has the most attractive colour, has a significant impact on the culture of some localities in this region, Nkang is also natural and nutritious as the others. But it has a short shelf-life like the other two and is consumed within a short period of its production. Thus people tend to consume it more when freshly made because most households cannot afford cooling devices to extend the keeping quality of the Nkang which could result in further fermentation with final sour taste. Because of its low alcoholic content, the beverage is consumed by both adults (the most elderly), children, those who have health problems and mostly preferred by some Christians. However, it is less popular as comparing with Sha-ah, not available as it is not frequently seen in the markets. The consumers complain that the little found in the markets is of poor quality which keeps dropping everyday, thus an indication of it disappearing and risk becoming extinct. Consumers also attest that if Nkang is clarified and its quality improved, then they will be happy and can even buy it at a higher price. While those who want it for cultural reason say that, they do not want the culture to die down so its production process can be improved so as to have quality Nkang which can sustain their culture. Hence further works can be carried out on how to improve its quality and conservative method so as to make it sustainable.

\section{Conflicts of Interest}

The authors declare no conflicts of interest regarding the publication of this paper. 


\section{References}

[1] Holzapfel, W. (2002) Appropriate Starter Culture Technologies for Small-Scale Fermentation in Developing Countries. International Journal of Food Microbiology, 75, 197-212. https://doi.org/10.1016/S0168-1605(01)00707-3

[2] Dicko, M.H. (2006) Sorghum Grain as Human Food in Africa: Relevance of Content of Starch and Amylase Activities. African Journal of Biotechnology, 5, 384-395.

[3] Chevassus-Agnes, S., Favier, J.C. and Joseph, A. (1979) Traditional Technology and Nutritive Value of Cameroon Sorghum Beers. Office National de la Recherche Scientifique et Technique du Cameroun, Cahiers, 2, 83-112.

[4] Ekundayo, J.A. (1969) The Production of Pito, a Nigerian Fermented Beverage. Journal of Food Technology, 4, 217-225. https://doi.org/10.1111/j.1365-2621.1969.tb01517.x

[5] Buemann, B., Toubro, S. and Astrup, A. (2002) The Effect of Wine or Beer versus a Carbonated Soft Drink, Served at a Meal, on Ad Libitum Energy Intake. International Journal of Obesity, 26, 1367-1372. https://doi.org/10.1038/sj.ijo.0802069

[6] De Castro, J.M. and Orozco, S. (1990) Moderate Alcohol Intake and Spontaneous Eating Patterns of Humans: Evidence of Unregulated Supplementation. The American Journal of Clinical Nutrition, 52, 246-253. https://doi.org/10.1093/ajcn/52.2.246

[7] Nduka, O. (1992) Commercialization of Fermented Foods in Sub-Saharan Africa. In: Applications of Biotechnology to Traditional Fermented Foods: Report of an Ad Hoc Panel of the Board on Science and Technology for International Development, National Academy Press, Washington DC, 165-170.

[8] Lyumugabe, L., Kamaliza, G., Bajyana, E. and Thonart, Ph. (2010) Microbiological and Physico-Chemical Characteristics of Rwandese Traditional Beer "Ikigage". African Journal of Biotechnology, 9, 4241-4246.

[9] Kayodé, A.P.P., et al. (2005) Quality of Farmer's Varieties of Sorghum and Derived Foods as Perceived by Consumers in Benin. Ecology of Food and Nutrition, 44, 271-294. https://doi.org/10.1080/03670240500187302

[10] Dicko, M.H., Gruppen, H., Traoré, A.S., Voragen, A.G.J. and van Berkel, W.J.H. (2006) Sorghum Grain as Human Food in Africa: Relevance of Content of Starch and Amylase Activities. African Journal of Biotechnology, 5, 384-395.

[11] Kahle, E.-M., Zarnkow, M. and Jacob, F. (2021) Beer Turbidity Part 1: A Review of Factors and Solutions. Journal of the American Society of Brewing Chemists, 79, 99-114. https://doi.org/10.1080/03610470.2020.1803468

[12] Novellie, L. and De Schaepdrijver, P. (1986) Modern Developments in Traditional African Beers. Progress in Industrial Microbiology, 23, 73-157.

[13] Mathias, T.R.S., de Mello, P.P.M. and SÃrvulo, E.F.C. (2014) Solid Wastes in Brewing Process: A Review. Journal of Brewing and Distilling, 5, 1-9. https://doi.org/10.5897/JBD2014.0043

[14] Osorio-MacÃas, D., PeÃarrieta, J.M. and Nilsson, L. (2017) Evaluation of Copper Content in Beers Obtained from Retail in Sweden. Journal of Brewing and Distilling, 7, 1-4. https://doi.org/10.5897/JBD2017.0049

[15] Sanni, A.I., Onilude, A.A., Fadahusi, I.F. and Afolabi, R.O. (1999) Microbial Deterioration of Traditional Alcoholic Beverages in Nigeria. Food Research International, 32, 163-167. https://doi.org/10.1016/S0963-9969(99)00068-X

[16] Hittner, J.B. (2009) Tension-Reduction Expectancies and Alcoholic Beverage Preferences Revisited: Associations to Drinking Frequency and Gender. International 
Journal of the Addictions, 30, 323-336. https://doi.org/10.3109/10826089509048729

[17] Zhu, M., Chen, Z., Luo, H.-B., Mao, X., Yang, Y., Tong, W.-H. and Huang, D. (2021) Study of the Phase Characteristics of Sichuan Bran Vinegar Fermentation Based on Flavor Compounds and Core Bacteria. Journal of the American Society of Brewing Chemists, 79, 201-211. https://doi.org/10.1080/03610470.2020.1794738

[18] Esmerino, E.A., Castura, J.C., Ferraz, J.P., et al. (2017) Dynamic Profiling of Different Ready-to-Drink Fermented Dairy Products: A Comparative Study Using Temporal Check-All-That-Apply (TCATA), Temporal Dominance of Sensations (TDS) and Progressive Profile (PP). Food Research International, 101, 249-258.

https://doi.org/10.1016/j.foodres.2017.09.012

[19] Heinz, H.A. and Elkins, J.T. (2019) Comparison of Unaged and Barrel Aged Whiskies from the Same Mash Bill Using Gas Chromatography/Mass Spectrometry. Journal of Brewing and Distilling, 8, 1-6. https://doi.org/10.5897/JBD2018.0051

[20] Atkinson, S. (2005) Beer Clarification. Membrane Technology, 2005, 8-10. https://doi.org/10.1016/S0958-2118(05)70458-4

[21] da Rosa Almeida, A., de Oliveira Brisola Maciel, M.V., Gandolpho, B.C.G., Machado, M.H., Teixeira, G.L., Bertoldi, F.C., Noronha, C.M., Vitali, L., Block, J.M. and Barreto, P.L.M. (2021) Brazilian Grown Cascade Hop (Humulus lupulus L.): LC-ESI-MS-MS and GC-MS Analysis of Chemical Composition and Antioxidant Activity of Extracts and Essential Oils. Journal of the American Society of Brewing Chemists, 79, 156-166. https://doi.org/10.1080/03610470.2020.1795586

[22] Makindara, J.R., Hella, J.P., Erbaugh, J.M. and Larson, D.W. (2013) Consumer Preferences and Market Potential for Sorghum Based Clear Beer in Tanzania. Journal of Brewing and Distilling, 4, 1-10. http://www.academicjournals.org/JBD https://doi.org/10.5897/JBD11.015

[23] Nso, E.J., Aseaku, J.N., et al. (2013) Comparison of the Mashing and Brewing Potentials of Crude Extracts of Abrus precatorius, Burnatia enneandra and Cadaba farinose. Journal of Brewing and Distilling, 4, 46-50.

http://www.academicjournals.org/JBD

https://doi.org/10.5897/JBD12.007

[24] Karlovic, A., Juric, A., Coric, N., Habschied, K., Krstanovic, V. and Mastanjevic, K. (2020) By-Products in the Malting and Brewing, Industries-Re-Usage Possibilities. Fermentation, 6, 82. https://www.mdpi.com/journal/fermentation https://doi.org/10.3390/fermentation6030082

[25] Tisekwa, B. (1989) Improvement of Traditional Manufacturing of Sorghum Beer (Mtama) in Tanzania. PhD Thesis, Ghent University, Belgium, 135-164.

[26] Udeh, H.O. and Kgatla, T.E. (2013) Role of Magnesium Ions on Yeast Performance during Very High Gravity Fermentation. Journal of Brewing and Distilling, 4, 19-45. http://www.academicjournals.org/JBD

https://doi.org/10.5897/JBD2013.0041

[27] Omari, I.O., Charnock, H.M., Fugina, A.L., Thomson, E.L. and McIndoe, J.S. (2021) Magnesium-Accelerated Maillard Reactions Drive Differences in Adjunct and All-Malt Brewing, Journal of the American Society of Brewing Chemists, 79, 145-155. https://doi.org/10.1080/03610470.2020.1795437

[28] Garshol, L.M. (2021) Pitch Temperatures in Traditional Farmhouse Brewing. Journal of the American Society of Brewing Chemists, 79, 181-186. https://doi.org/10.1080/03610470.2020.1805699

[29] Faparusi, S.I., Olofinboba, M.O. and Ekwundayo, J.A. (2001) The Microbiology of Burukutu Beer. Zeitschrift für Allgemeine Mikrobiologie, 13, 563-568. https://doi.org/10.1002/jobm.19730130705 